Pacific Journal of Mathematics

GALOIS COHOMOLOGY OF ABELIAN GROUPS 


\title{
GALOIS COHOMOLOGY OF ABELIAN GROUPS
}

\section{DALTON TARWATER}

\begin{abstract}
Normal and separable algebraic extensions of abelian groups have been defined in a manner similar to that of the field theory. In this paper it is shown that if $N$ is a normal algebraic extension of the torsion group $K=\sum K_{p}$, where the $p$-components $K_{p}$ of $K$ are cyclic or divisible, and if $G$ is the group of $K$-automorphisms of $N$, then there is a family $\left\{G_{E}\right\}_{E} \in_{X}$ of subgroups of $G$ such that $\left\{G,\left\{G_{E}\right\}_{E} \in_{X}, N\right\}$ is a field formation.
\end{abstract}

All groups mentioned are abelian. If $K$ is a subgroup of $E$, then $A_{K}(E)$ denotes the group of $K$-automorphisms of $E$. If $S$ is a subgroup of the automorphism group $A(E)$ of $E$, then $E^{S}$ is the subgroup of $E$ fixed by $S . E$ is an algebraic extension of $K$ if every $e \in E$ satisfies an equation $n e=k \neq 0, k \in K . E$ is a normal extension of $K$ in an algebraic closure $D$ of (minimal divisible group containing) $K$ if every $K$-automorphism of $D$ induces an automorphism of $E$ and $E$ is a separable extension of $K$ if for every $e \in E, e \notin K$, there is a $\sigma \in A_{K}(D)$ such that $e \neq \sigma(e) \in E$. A formation is a field formation [1] if it satisfies:

Axiom I. For each Galois extension $F / E$,

$$
H^{1}(F / E)=H^{1}\left(G_{E} / G_{F}, F\right)=0 .
$$

The following are proved in [6]:

I (THEOREM 8). Let $N$ be a normal and separable extension of $K$ in $D$ and let $E(\neq N)$ be an extension of $K$ in $N$. $E$ is a normal extension of $K$ if and only if $A_{E}(N)$ is a normal subgroup of $A_{K}(N)$ and then

$$
A_{K}(E) \cong A_{K}(N) / A_{E}(N)
$$

II (THEOREM 11). If $G^{\prime}$ is a closed subgroup of $G$ (in the topology defined below) and $E=N^{G^{\prime}}$, then $G^{\prime}=A_{E}(N)$.

We now state the

III Theorem. Let $K=\sum K_{p}$ be a torsion group such that $K_{2}$ is divisible or trivial and for a prime $p \geqq 3, K_{p}$ is divisible or cyclic. If $N$ is a normal extension of $K$ in an algebraic closure $D$ of $K$, if $G=A_{K}(N)$, and if $X$ is the class of groups $E$ such that $K \subseteq E \subseteq N$ 
and $G_{E}=A_{E}(N)$ is of finite index in $G$, then $\left\{G,\left\{G_{E}\right\}_{E \in X}, N\right\}$ is a field formation.

Proof. Since $K$ is a torsion group, it follows (page 54 of [6]) that $N$ is a separable extension of $K . G$ is the complete direct product of the groups $A_{K_{p}}\left(N_{p}\right)$ which are abelian, being cyclic if $N_{p}$ is cyclic or being isomorphic to a subgroup of the multiplicative group of $p$-adic units of $N_{p}=D_{p} \cong Z\left(p^{\infty}\right)$ and $K_{p}$ is cyclic.

Let $\mathscr{L}$ be the class of groups $L$ such that $K \cong L \subseteq N$ and if $K_{p}$ is cyclic while $N_{p}=D_{p}$ then $L_{p}$ is cyclic. Topologize $G$ by taking as a filter base for the neighborhoods of 0 all groups $G_{L}=A_{L}(N)$ with $L \in \mathscr{L}$.

Every member of $X$ is in $\mathscr{L}$. For if $E \in X$, then by I, $G / G_{E} \cong$ $A_{K}(E) \cong \pi A_{K_{p}}\left(E_{p}\right)$ is a finite group. So $E_{p}=K_{p}$ for almost all primes $p$ and if $E_{p} \neq K_{p}$ then $E_{p}$ is cyclic (otherwise $A_{K_{p}}\left(E_{p}\right)$ is of the power of the continuum). Hence $E \in \mathscr{L}$.

We have

A. If $E$ and $E^{\prime}$ are in $X$, then $G_{E} \cap G_{E^{\prime}}=G_{E+E^{\prime}}$ and $E+E^{\prime}$ is in $X$.

B. If $E \in X$ and $G_{E} \subseteq G^{\prime} \subseteq G$, then $G^{\prime}=G_{E^{\prime}}$, where $E^{\prime}=N^{G^{\prime}} \in X$.

Proof of B. $G^{\prime}$ is of finite index and is closed in the topology on $G$. An application of II completes the proof.

C. For $E \in X$, every conjugate of $G_{E}$ equals $G_{E}$.

D. For each $x \in N, \Gamma(x)=\{\gamma(x) \mid \gamma \in G\}$ is one of the $G_{E}$ with $E \in X$.

Proof of $D . \quad\{K, x\}$, the group generated by $K$ and $x$, is in $X$. For if $\gamma^{\prime} \in \gamma G_{\{K, x\}}$ then $\gamma^{\prime}(x)=\gamma(x)$; but there are only finitely many members of $\Gamma(x)$ since there are only finitely many elements of $N$ which are not in $K$ and have the same order as $x$. So $G_{\{K, x\}}$ is of finite index. Also, $G_{\{K, x\}} \subseteq \Gamma(x) \subseteq G$. So by $B, \Gamma(x)$ is one of the $G_{E}$ with $E \in X$.

Statements A thru D establish that $\left\{G,\left\{G_{E}\right\}_{E} \in_{X}, N\right\}$ is a formation [5]. It remains to be proved that if $G_{F} \subseteq G_{E}$ for $E$ and $F$ in $X$, then $H^{1}(F / E)=H^{1}\left(A_{E}(F), F\right)=0$. The proof will be established first for cyclic $p$-groups $(p \neq 2)$. The following lemma will facilitate this proof. The proof of the lemma will be found below. 
Lemma. If $p$ is an odd prime and $M=\sum\left(1+p^{m}\right)^{i}, i=0,1, \cdots$. $p^{n-m}-1$, where $n>m \geqq 1$, then $p^{n-m}$ is an exact divisor of $M$.

Now let $F_{p}$ by cyclic of order $p^{n}$ and algebraic over its subgroup $E_{p}$ of order $p^{m}, m \geqq 1$. If $t \in A_{E_{p}}\left(F_{p}\right)$ is defined by $t(x)=\left(1+p^{m}\right) x$, then $t$ generates $A_{E_{p}}\left(F_{p}\right)$. By Theorem 7.1 of [4],

$$
H^{1}\left(A_{E_{p}}\left(F_{p}\right), F_{p}\right) \cong\left\{f \in F_{p} \mid M f=0\right\} /\left\{(t-1) f \mid f \in F_{p}\right\},
$$

where $M f=\sum\left(1+p^{m}\right)^{i} f, i=0,1, \cdots, p^{n-m}-1$, and $(t-1) f=p^{m} f$. From the lemma, $M f=0$ implies $f=p^{m} f^{\prime}$ for some $f^{\prime} \in F_{p}$. Thus $H^{1}\left(A_{E_{p}}\left(F_{p}\right), F_{p}\right)=0$, concluding the primary cyclic case.

To complete the proof of the theorem, let $E$ and $F$ be in $X$ such that $G_{F} \subseteq G_{E}$, i.e., $F / E$ is a Galois extension. Then by Theorem 10.1 of [2]

$$
H^{1}(F / E)_{p}=H^{1}\left(A_{E_{p}}\left(F_{p}\right), F_{p}\right)=0
$$

for each prime $p$ and therefore $H^{1}(F / E)=0 . \quad\left\{G,\left\{G_{E}\right\}_{E} \epsilon_{X}, N\right\}$ is a field formation.

Proof of lemma (suggested by A. A. Gioia). The series defining $M$ is geometric so $p^{m} M=\left(1+p^{m}\right)^{p^{n-m}}-1$. By Theorem 4-5 of [3], $p^{n}$ divides the right hand side of this equation. If $p^{n+1}$ also divides $p^{m} M$, then Theorem $4-5$ of [3]-which requires $p \neq 2$-can be applied again to yield:

$$
1+p^{m} \equiv 1 \bmod p^{n+1-(n-m)}
$$

which is false. The lemma is proved.

\section{REFERENCES}

1. E. Artin and J. Tate, Class Field Theory, Harvard, 1961.

2. H. Cartan and S. Eilenberg, Homological Algebra, Princeton University Press, Princeton, 1956.

3. W. J. LeVeque, Topics in Number Theory, Vol. I, Addison-Wesley, Reading, 1956.

4. S. MacLane, Homology, Springer-Verlag, Berlin, 1963.

5. J. P. Serre, Corps Locaux, Hermann, Paris, 1962.

6. D. Tarwater, Galois theory of abelian groups, Math. Zeit. 95 (1967), 50-59.

Received February 20, 1967. Partly supported by NFS Grant GP-2214.

WESTERN MICHIGAN UNIVERSITY

KalamaZoo, MichigaN

AND

North Texas State University 



\section{PACIFIC JOURNAL OF MATHEMATICS}

\section{EDITORS}

\section{H. ROYDEN}

Stanford University

Stanford, California

\section{J. P. Jans}

University of Washington

Seattle, Washington 98105

\section{J. DUGUNDJI}

Department of Mathematics

Rice University

Houston, Texas 77001

RICHARD ARENS

University of California

Los Angeles, California 90024

\section{ASSOCIATE EDITORS}
E. F. BeCKenbaCH
B. H. NeumanN
F. WOLF
K. YosIDA

\section{SUPPORTING INSTITUTIONS}

UNIVERSITY OF BRITISH COLUMBIA CALIFORNIA INSTITUTE OF TECHNOLOGY UNIVERSITY OF CALIFORNIA MONTANA STATE UNIVERSITY UNIVERSITY OF NEVADA NEW MEXICO STATE UNIVERSITY OREGON STATE UNIVERSITY UNIVERSITY OF OREGON OSAKA UNIVERSITY UNIVERSITY OF SOUTHERN CALIFORNIA
STANFORD UNIVERSITY UNIVERSITY OF TOKYO UNIVERSITY OF UTAH WASHINGTON STATE UNIVERSITY UNIVERSITY OF WASHINGTON

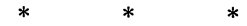

AMERICAN MATHEMATICAL SOCIETY CHEVRON RESEARCH CORPORATION TRW SYSTEMS

NAVAL ORDNANCE TEST STATION 


\section{Pacific Journal of Mathematics}

\section{Vol. 24, No. $1 \quad$ May, 1968}

Harry P. Allen, Lie algebras of type $D_{4}$ over algebraic number fields ...... 1

Charles Ballantine, Products of positive definite matrices. II............ 7

David W. Boyd, The spectral radius of averaging operators ............ 19

William Howard Caldwell, Hypercyclic rings ................... 29

Francis William Carroll, Some properties of sequences, with an application

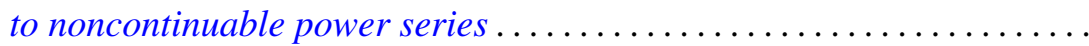

David Fleming Dawson, Matrix summability over certain classes of

sequences ordered with respect to rate of convergence ........... 51

D. W. Dubois, Second note on David Harrison's theory of preprimes. . . . . 57

Edgar Earle Enochs, A note on quasi-Frobenius rings.............. 69

Ronald J. Ensey, Isomorphism invariants for Abelian groups modulo bounded groups ................................ 71

Ronald Owen Fulp, Generalized semigroup kernels ................ 93

Bernard Robert Kripke and Richard Bruce Holmes, Interposition and approximation ................................. 103

Jack W. Macki and James Sai-Wing Wong, Oscillation of solutions to second-order nonlinear differential equations ..................

Lothrop Mittenthal, Operator valued analytic functions and generalizations

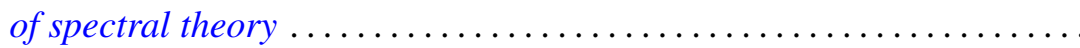

T. S. Motzkin and J. L. Walsh, A persistent local maximum of the pth power deviation on an interval, $p<1 \ldots \ldots \ldots \ldots \ldots \ldots \ldots \ldots \ldots \ldots . \ldots \ldots$

Jerome L. Paul, Sequences of homeomorphisms which converge to homeomorphisms ...........................

Maxwell Alexander Rosenlicht, Liouville's theorem on functions with elementary integrals.

Joseph Goeffrey Rosenstein, Initial segments of degrees .

$\mathrm{H}$. Subramanian, Ideal neighbourhoods in a ring ............

Dalton Tarwater, Galois cohomology of abelian groups . .

James Patrick Williams, Schwarz norms for operators ... .

Raymond Y. T. Wong, A wild Cantor set in the Hilbert cube. 